\title{
CLORETO DE N-(2-HIDROXIL) PROPIL-3-TRIMETIL AMÔNIO QUITOSANA COMO ADSORVENTE DE CORANTES REATIVOS EM SOLUÇÃO AQUOSA
}

\author{
Valfredo T. Fávere* \\ Departamento de Química, Universidade Federal de Santa Catarina, CP 476, 88040-900 Florianópolis - SC, Brasil \\ Humberto G. Riella \\ Departamento de Engenharia Química, Universidade Federal de Santa Catarina, 88040-900 Florianópolis - SC, Brasil \\ Sirlei da Rosa \\ Universidade Tecnológica Federal do Paraná, Curitiba - PR, Brasil
}

Recebido em 30/9/09; aceito em 20/3/10; publicado na web em 9/8/10

\begin{abstract}
CHITOSAN-N-2-HYDROXYPROPYL TRIMETHYL AMMONIUM CHLORIDE AS ADSORBENT FOR THE REMOVAL OF THE REACTIVE DYE FROM AQUEOUS SOLUTIONS. The quaternary chitosan was synthesized by reaction of chitosan with glycidyl trimethylammonium chloride. it was characterized by infrared spectra and conductometric titration. Adsorption of reactive blue 4 (RB4) and reactive red 120 (RR120) by quaternary chitosan was studied from aqueous medium. Two kinetic adsorption models were tested: pseudo first-order and pseudo second-order. The experimental data best fitted the pseudo second-order model. The Langmuir isotherm model provided the best fit to the equilibrium data in the concentration range investigated and the maximum adsorption capacity determined was $415 \mathrm{mg}$ (RR120) and $637 \mathrm{mg}$ (RB4) of reactive dye per gram of adsorbent.
\end{abstract}

Keywords: reactive dye; quaternary chitosan; adsorption.

\section{INTRODUÇÃO}

A água é um recurso natural essencial aos processos bioquímicos dos seres vivos e representa um fator importante nas atividades industriais de vários bens de consumo. O seu uso de forma racional, evitando o desperdício e a poluição não deveria ser motivo de preocupação somente aos ambientalistas, mas também, para as instituições governamentais e para o processo produtivo, pois $1 / 6$ da população mundial não tem acesso à água potável. ${ }^{1}$

Algumas formas de amenizar o problema da inevitável escassez da água seriam reduzir a poluição causada pelo processo industrial através do tratamento de seus efluentes, bem como, a implantação de projetos de reuso da água, desse modo, recuperando insumos e subprodutos. ${ }^{1}$

Há de se referir que as indústrias têxteis consomem um volume significativo de água no processo de tingimentos das fibras e tais águas são altamente coloridas devido à presença de corantes que não se fixam na fibra durante o processo de tingimento, com isso podendo afetar o processo de fotossíntese em virtude da diminuição da transparência da água, o que dificulta a entrada dos raios solares. ${ }^{2,3}$

Embora muitas moléculas orgânicas sejam degradadas, outras tantas são estáveis e, em função da sua estrutura química complexa, não são totalmente degradadas. ${ }^{4}$ Os corantes sintéticos são, na maioria, xenobióticos, ou seja, os micro-organismos presentes em rios e lagos não contêm enzimas específicas para degradação deste tipo de composto sob condições aeróbicas; sendo que sob condições anaeróbicas, a degradação do corante se processa muito lentamente. ${ }^{5}$ Além desse fato, estudos têm mostrado que algumas classes de corantes, principalmente azocorantes e seus subprodutos, podem ser carcinogênicos e/ou mutagênicos e, portanto, podendo causar toxidade aos organismos aquáticos. . $^{3,6,7}$

O tratamento convencional dos efluentes têxteis envolve um processo físico-químico de coagulação/floculação. O sistema apresenta uma eficiência relativamente alta, o qual pode ser utilizado isoladamente ou combinado com o tratamento biológico, assim promovendo

\footnotetext{
*e-mail: favere@qmc.ufsc.br
}

uma elevada remoção da cor de efluentes de indústrias têxteis. ${ }^{8-10}$ No entanto, este processo apresenta como desvantagem o grande volume de lodo gerado uma vez que o teor de corantes adsorvido no lodo é bastante elevado, além das demais substâncias utilizadas no processo têxtil. ${ }^{3,11}$

Outros processos têm sido usados para remoção de corantes de efluentes têxteis, como oxidação avançada, filtração por membrana, osmose reversa e adsorção empregando geralmente carvão ativo. ${ }^{12-15}$

A grande vantagem do processo de adsorção em relação aos outros processos é a pouca geração de resíduos e a possibilidade de reutilização do adsorvente. ${ }^{16-19}$

Biopolímeros têm sido considerados uma classe promissora de bioadsorventes usados para remoção de poluentes orgânicos e inorgânicos de ambiente aquático. Quitosana, principal derivado da quitina, que é um dos biopolímeros mais abundante da natureza, tem sido extensivamente utilizada como biosorvente em meio aquoso. ${ }^{20}$

A quitosana tem mostrado excelentes propriedades adsorventes de corantes aniônicos em meio ácido devido à protonação dos grupos amino na matriz do polímérica, que pode adsorver o corante em solução por interação iônica entre os grupos $-\mathrm{NH}_{3}{ }^{+}$e os grupos $-\mathrm{SO}_{3}^{-}$ dos corantes. No entanto, esta interação depende do $\mathrm{pH}$ da solução, o qual deve ser ajustado em torno de 3 para protonação completa dos grupos amino. ${ }^{21-26}$ Por conseguinte, o pH da solução é um dos parâmetros mais importante que afeta o processo de adsorção quando se emprega quitosana como adsorvente. ${ }^{19}$

Os grupos amino livres possibilitam inúmeras modificações químicas da quitosana e, consequentemente, isso pode afetar suas características como adsorvente. ${ }^{27,28}$ Uma das modificações bastante interessante é transformar a quitosana num sal quaternário e tornar a adsorção de corantes aniônicos independente do pH. A independência do $\mathrm{pH}$ diminui o número de etapas no processo de remoção dos corantes dos efluentes e o consumo de reagentes químicos nos tanques de equalização, dessa forma, facilitando o reciclo destas águas e diminuindo os custos de tratamento.

Neste sentido, o presente trabalho propõe preparar o sal quaternário de quitosana, cloreto de N-(2-hidroxil) propil-3-trimetil amônio 
quitosana, reticulando com glutaraldeído, e avaliar suas propriedades adsortivas em relação aos corantes Reativos Azul 4 e Vermelho 120.

\section{PARTE EXPERIMENTAL}

\section{Materiais}

A quitosana empregada para preparação do adsorvente foi obtida da Purifarma (Brasil) com um grau de desacetilação de $90 \%$; cloreto de glicidil trimetil amônio foi adquirido da Fluka Biochemica (Switzerland); os corantes Reativos Azul 2 (RB4, 35\% pureza) e Vermelho 120 (RR120, 60\% pureza) foram adquiridos da Aldrich (USA). A Figura 1 ilustra a estrutura dos corantes reativos.

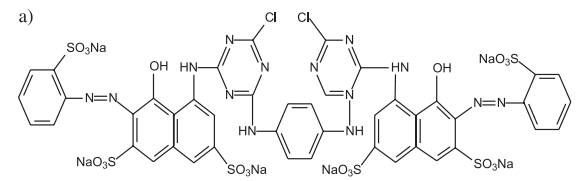

b)

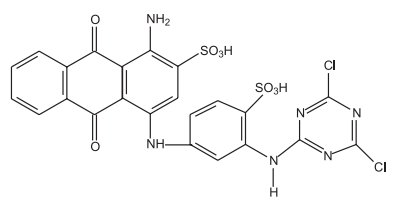

Figura 1. Corante reativo vermelho 120 (a). Corante reativo azul 4 (b)

\section{Instrumentação}

$\mathrm{O}$ espectro no infravermelho foi obtido usando-se um espectrofotômetro Perkim Elmer PC FTIR 16. A quantidade de grupos quaternários foi determinada por titulação condutométrica usando-se um condutivímetro Mettler MC 226 e um titulador automático da Schott Geräte, modelo T 80/20. Um espectrômetro UV-Vis Micronal modelo B542 foi empregado para determinar a concentração dos corantes em solução.

\section{Preparação do cloreto de N-(2-hidroxil) propil-3-trimetil amônio quitosana}

Aproximadamente $20 \mathrm{~g}$ de quitosana foram suspensas em $200 \mathrm{~mL}$ de água destilada e a mistura foi levada ao aquecimento a $60{ }^{\circ} \mathrm{C}$, sob agitação. Foram adicionadas, ao sistema, três porções de $15 \mathrm{~g} /$ adição de cloreto de glicidil trimetil amônio em intervalos de 2,5 h. Após 24 $\mathrm{h}$ de reação, sob as mesmas condições de aquecimento e agitação, o sistema foi deixado em repouso até atingir a temperatura ambiente e o pH foi ajustado para 5,4 com ácido clorídrico. Com o objetivo de remover o cloreto de glicidil trimetil amônio que não reagiu, o produto da reação foi precipitado em acetona..$^{29} \mathrm{e}$, em seguida, foi filtrado a vácuo. No intuíto de tornar o material insolúvel em meio aquoso, 25 g do cloreto de N-(2-hidroxil) propil-3-trimetil amônio quitosana foram reticuladas com $25 \mathrm{~mL}$ de glutaraldeído $25 \%$, suspensos em $250 \mathrm{~mL}$ de álcool etílico. O sistema foi mantido sob agitação por 5 h e, em seguida, filtrado a vácuo. O material foi liofilizado e, após, tamizado em peneiras com aberturas de 0,212 a 0,053 mm. A Figura 2 ilustra a estrutura do sal quaternário de quitosana (SQQ).

\section{Soluções estoques dos corantes e curvas de calibração}

Soluções estoques de $2000 \mathrm{mg} \mathrm{L}^{-1}$ dos corantes foram preparadas levando-se em consideração o grau de pureza de cada corante reativo, diluído com água destilada. A partir das soluções estoques, foram preparadas soluções padrão, para construção da curva de calibração

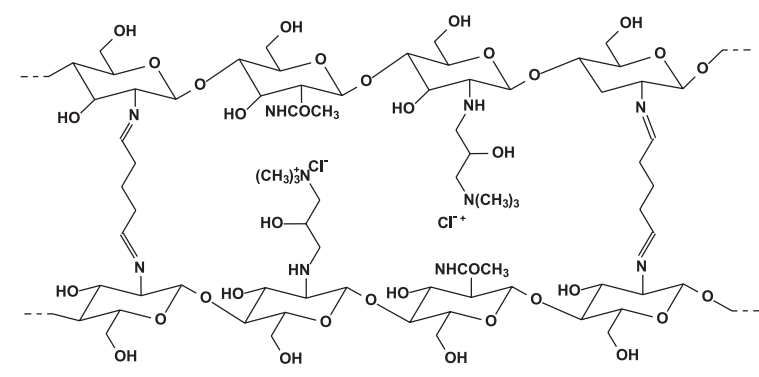

Figura 2. Estrutura do cloreto de $N$-(2-hidroxil) propil-3-trimetil amônio quitosana reticulado

(10 a $50 \mathrm{mg} \mathrm{L}^{-1}$ ) de cada corante reativo, para a determinação da concentração dos corantes em solução, após os experimentos de adsorção.

\section{Experimentos de adsorção}

A remoção de corantes reativos pelo processo de adsorção em meio aquoso depende de vários fatores, tais como, quantidade de adsorvente, tamanho de partícula, $\mathrm{pH}$, tempo de contato, velocidade de agitação e temperatura. Nos experimentos, a temperatura, velocidade de agitação e tamanho de partícula foram mantidos constantes.

Uma quantidade conhecida de adsorvente e um volume de solução dos corantes foram colocados em erlenmeyers fechados de $125 \mathrm{~mL}$. O sistema permaneceu sob agitação, numa incubadora termostatizada, a $25^{\circ} \mathrm{C}$. O material foi separado da solução por decantação e o corante não adsorvido foi determinado por espectrofotometria UV-Vis, usando-se uma curva de calibração no $\lambda_{\text {max }}$ de cada corante.

A quantidade adsorvida de corante foi determinada empregandose a equação:

$$
Q_{e}=\frac{\left(C_{o}-C_{f}\right) \cdot V}{W}
$$

onde, $Q_{\mathrm{e}}$ é a quantidade de íons adsorvida no equilíbrio $\left(\mathrm{mg} \mathrm{g}^{-1}\right), C_{\mathrm{o}}$ é a concentração inicial de íons em solução $\left(\mathrm{mg} \mathrm{L}^{-1}\right), C_{\mathrm{f}}$ é a concentração remanescente dos corantes em solução, $V$ é o volume da solução (L) e $W$ é a massa do adsorbato (g).

$\mathrm{O}$ efeito do $\mathrm{pH}$ foi estudado empregando-se $50 \mathrm{mg}$ de adsorvente, $50 \mathrm{~mL}$ de solução de corante reativo $170 \mathrm{mg} \mathrm{L}^{-1}$, velocidade de agitação $250 \mathrm{rpm}$ e ajustando-se o $\mathrm{pH}$ com $\mathrm{CH}_{3} \mathrm{COOH} / \mathrm{CH}_{3} \mathrm{COONa}(\mathrm{pH} 3$, 4, e 5); $\mathrm{NaH}_{2} \mathrm{PO}_{4} / \mathrm{Na}_{2} \mathrm{HPO}_{4}(\mathrm{pH} 6,7$ e 8$) \mathrm{NH}_{4} \mathrm{OH} / \mathrm{NH}_{4} \mathrm{Cl}$ ( $\mathrm{pH} 9$ e 10).

A cinética de adsorção foi conduzida empregando-se frascos fechados contendo $100 \mathrm{mg}$ de adsorvente, $100 \mathrm{~mL}$ de solução dos corantes $500 \mathrm{mg} \mathrm{L}^{-1}$ e tamponada em $\mathrm{pH}$ 4.0. Em tempos predeterminados, o shaker foi desligado e, imediatamente, uma alíquota foi removida e a absorbância foi lida. Após a leitura, a solução retornou ao fraco original.

As isotermas de equilíbrio foram obtidas com $100 \mathrm{mg}$ de adsorvente e $100 \mathrm{~mL}$ de uma solução tamponada em $\mathrm{pH} 4,0$, força iônica $0,1 \mathrm{~mol} \mathrm{~L}^{-1} \mathrm{e}$ as concentrações dos corantes variaram de 100 a 1000 $\mathrm{mg} \mathrm{L}^{-1}$. O sistema foi mantido a temperatura constante $25,0 \pm 0,5$ ${ }^{\circ} \mathrm{C}$ e sob agitação de $250 \mathrm{rpm}$ até atingir o equilíbrio de adsorção. Alíquotas foram removidas, diluídas em um frasco volumétrico e as concentrações determinadas por medidas de absorção no UV-Vis.

\section{RESULTADOS E DISCUSSÃO}

O sal quaternário obtido tinha uma aparência de gel, cor amarelada e com odor característico de compostos de amônio. Após a secagem e reticulação com glutaraldeído, o sal adquiriu uma cor vermelho-tijolo e manteve o mesmo odor. A caracterização do novo 
adsorvente foi realizada através de análises de infravermelho (IV) e titulação condutométrica. Os resultados obtidos destas análises estão descritos a seguir.

O espectro na região do IV do sal quaternário de quitosana é ilustrado na Figura 3. Os principais grupos característicos da quitosana são $\mathrm{C}-\mathrm{NH}_{2}$ da amina primária, $-\mathrm{C}-\mathrm{OH}$ de álcool primário, $-\mathrm{C}=\mathrm{O}$ originário da quitina. ${ }^{30}$ As bandas obtidas no IV da quitosana e do novo material adsorvente foram muito similares, porém apresentaram pequenas diferenças que possibilitaram a identificação do grupo quaternário inserido na quitosana. Comparando-se o espectro de infravermelho da quitosana e do novo material adsorvente, foi possível perceber que ocorreu o surgimento de uma nova banda em $1482 \mathrm{~cm}^{-1}$, que pode ser atribuída à deformação angular assimétrica dos grupos metila do nitrogênio quaternário.

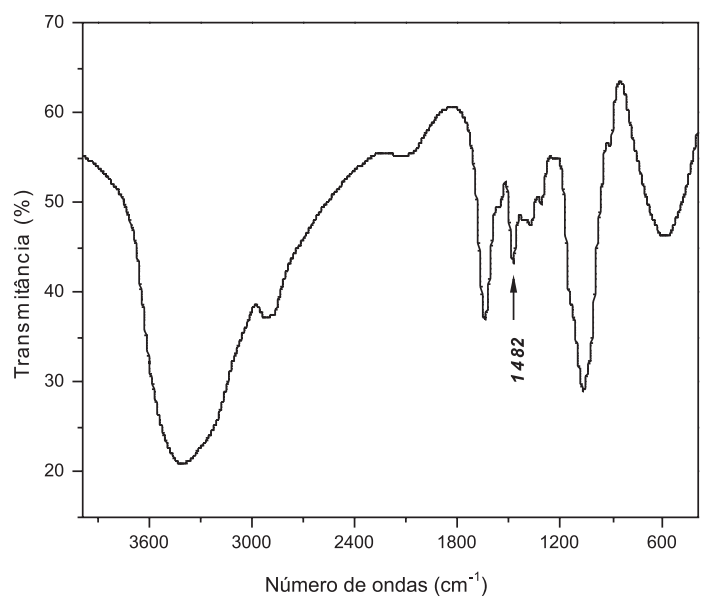

Figura 3. Espectro no infravermelho do sal quaternário de quitosana (SQQ)

A Figura 4 ilustra a titulação condutométrica do sal quaternário de quitosana com solução padrão de $\mathrm{AgNO}_{3} 0,100 \mathrm{~mol} \mathrm{~L}^{-1}$. A titulação foi realizada em triplicata para se determinar a quantidade de contraíons cloretos presente e relacioná-la com os grupos quaternários imobilizados na quitosana. Para a titulação, foi gasto um volume médio de 5,64 $\mathrm{mL}$ de $\mathrm{AgNO}_{3}$, o que corresponde a 2,59 mmol de grupos quaternários por grama de SQQ, correspondendo a um grau de substituição de 0,46 .

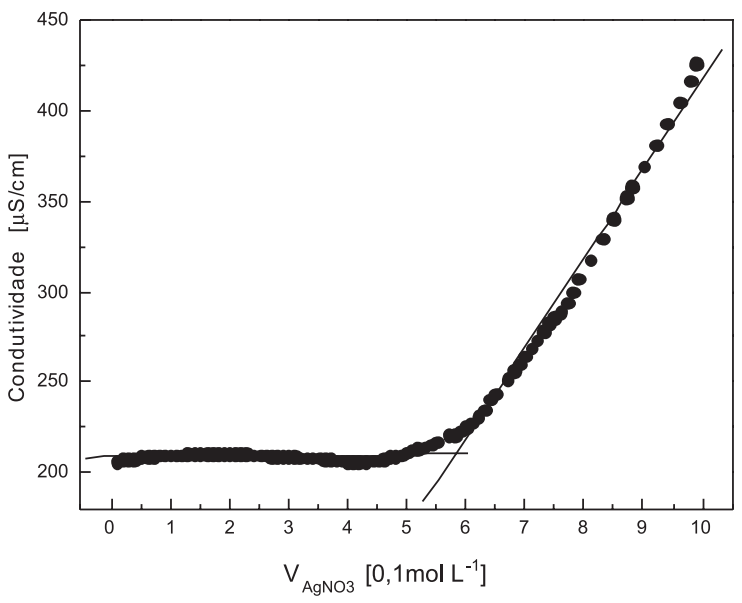

Figura 4. Titulação condutimétrica do $\mathrm{SQQ}$ pelo $\mathrm{AgNO}_{3}$

\section{Dependência do pH na adsorção}

$\mathrm{O}$ pH é um dos parâmetros mais importante que afeta o processo de adsorção. A análise da Figura 5 mostra que a quantidade de corante adsorvida em função do $\mathrm{pH}$ teve uma pequena variação na adsorção em toda faixa de $\mathrm{pH}$ estudada.

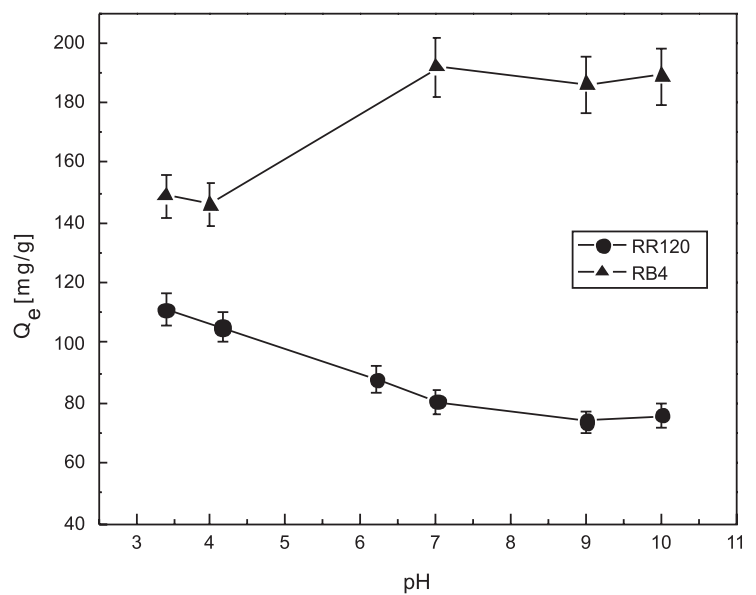

Figura 5. Quantidade adsorvida de corante RR120 e RB4 pelo SQQ em diferentes valores de $\mathrm{pH}$ da soluções

$\mathrm{O}$ adsorvente possui o grupo funcional $-\mathrm{R}_{3} \mathrm{~N}^{+} \mathrm{Cl}^{-}$, o qual é considerado um grupo fortemente básico e, portanto, a capacidade adsorvida é independente do $\mathrm{pH}$. Os contraíons cloretos presentes no adsorvente poderâo ser trocados por uma quantidade equivalente de outros íons em solução. Os corantes RR120 e RB4 são corantes aniônicos e possuem um grupo sulfônico $\left(-\mathrm{SO}_{3} \mathrm{H}\right)$, derivado de um ácido forte. São produzidos na forma de sal sódico e solúvel em água. Dessa forma, o processo de adsorção entre o sal quaternário de quitosana (SQQ) e os corantes ocorre via interação iônica entre os sítios adsorventes $-\mathrm{R}_{3} \mathrm{~N}^{+}$e os grupos aniônicos $\mathrm{SO}_{3}^{-}$dos corantes.

Era esperado que a adsorção fosse independende do $\mathrm{pH}$ em toda a faixa estudada. No entanto, após a reticulação, ainda permanecem grupos amino remanescentes que não reagiram com glutaraldeído, assim produzindo uma pequena dependência do $\mathrm{pH}$ no processo de adsorção.

Estudos realizados com microesferas de quitosana reticulada e o corante RO16 têm indicado que a adsorção é dependente do $\mathrm{pH}$. $\mathrm{Em} \mathrm{pH}<3$, a quitosana está completamente protonada e a adsorção é atribuída principalmente à interação iônica entre os grupos protonados do polímero e os grupos sulfonatos do corante; enquanto que, em meio alcalino, a adsorção diminui significadamente em função da cadeia polimérica não estar positivamente carregada e não poder interagir com as cargas negativas do corante. ${ }^{22,29}$

\section{Cinética de adsorção}

Os experimentos de cinética tiveram como objetivo estudar o mecanismo que controla o processo cinético e encontrar o tempo em que ocorre o equilíbrio adsorvente-corantes, bem como, a partir dos valores encontrados, utilizá-los nos experimentos de isotermas de adsorção.

A Figura 6 sinaliza a variação da concentração da fase líquida ( $\left.\mathrm{C}_{\mathrm{t}} / \mathrm{C}_{\mathrm{o}}\right)$ dos corantes RR120 e RB4 em função do tempo de contato com o adsorvente; $\mathrm{C}_{\mathrm{t}}$ e $\mathrm{C}_{\mathrm{o}}$ correspondem à concentração do corante em um tempo t e à concentração inicial, respectivamente. $\mathrm{O}$ equilíbrio, praticamente, foi alcançado em 19 h (RB4) e 56 h (RR120), sendo esse tempo empregado na obtenção das isotermas de adsorção.

Comparando-se as frações removidas dos corantes RR120 e RB4, observou-se que, aos $200 \mathrm{~min}$ foram removidos 35 e $75 \%$ da concentração inicial dos corantes, respectivamente. A menor remoção do corante RR120 é atribuída à natureza do corante e será discutida nas isotermas de adsorção. 


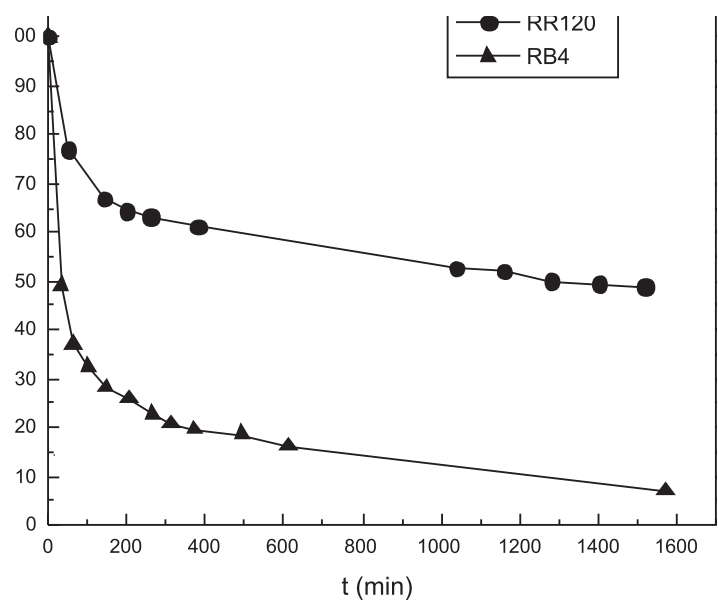

Figura 6. Variação da concentração da solução dos corantes RR120 e RB4 em função do tempo, $C_{o}=500 \mathrm{mg} \mathrm{L}^{-1}, \mathrm{~m}=100 \mathrm{mg}, \mathrm{V}=100 \mathrm{~mL}, \mathrm{pH}=4, \mu=$ $0,1 \mathrm{~mol} \mathrm{L^{-1 }}$, velocidade de agitação $250 \mathrm{rpm}$, temperatura $25^{\circ} \mathrm{C}$

Para avaliar o mecanismo que controla o processo, os modelos de pseudoprimeira ordem e pseudossegunda ordem foram testados, e a validade dos modelos foi verificada pelas equações destes modelos. ${ }^{29,31}$ Uma boa correlação dos dados cinéticos comprova o possível mecanismo cinético de adsorção na fase sólida.

O modelo de pseudoprimeira ordem, pode ser interpretado pelo gráfico do $\log \left(\mathrm{q}_{\mathrm{e}}-\mathrm{q}_{\mathrm{t}}\right)$ vs t. A equação linear do modelo cinético forneceu as equações RR120: $Y=2,20-6,70.10^{-4}\left(R^{2}=0,991\right)$ e RB4: $\mathrm{Y}=2,36-5,00 \cdot 10^{-3}\left(\mathrm{R}^{2}=0,954\right)$.

Analisando as equações, estas não apresentam boa linearidade e uma discrepância foi observada, os valores experimentais de $Q_{e}$ não foram iguais aos valores calculados. Quando estes valores foram comparados com os dados experimentais, foram observados desvios de 39 e $38 \%$, respectivamente.

A equação de pseudossegunda ordem pode ser interpretada pelo gráfico do $\left(\mathrm{t}_{\mathrm{q}} \mathrm{q}\right)$ vs $\mathrm{t}$. A equação linear do modelo cinético forneceu as equações RR120: $\mathrm{Y}=0,50+3,80 \cdot 10^{-3}\left(\mathrm{R}^{2}=0,996\right)$ e $\mathrm{RB} 4: \mathrm{Y}=$ $6,50 \cdot 10^{-2}+2,60 \cdot 10^{-3}\left(R^{2}=0,999\right)$.

Os gráficos forneceram excelentes linearidades com um $\mathrm{R}^{2} \approx 0,999 ;$ portanto, este modelo foi selecionado para calcular os parâmetros cinéticos. As constantes de velocidade $\left(\mathrm{k}_{2}\right)$ obtidas foram $2,82 \times 10^{-5}$ e $1,04 \times 10^{-4} \mathrm{~g} \mathrm{mg}^{-1} \mathrm{~min}^{-1}$ para os corantes RR120 e RB4, respectivamente. Comparando-se os valores experimentais de $Q_{e}$ de 258 e $362 \mathrm{mg} \mathrm{g}^{-1}$ com os valores calculados 265 e $385 \mathrm{mg} \mathrm{g}^{-1}$, estes mostraram uma boa concordância, com desvios de 2,7 e 6,2\%, respectivamente. $\mathrm{O}$ mecanismo cinético indicou que a velocidade de adsorção dos corantes reativos pelo adsorvente depende da quantidade destes na superfície do adsorvente e da quantidade adsorvida no equilíbrio.

\section{Isotermas de adsorção}

Para otimizar um sistema de adsorção de um corante em meio aquoso é importante estabelecer a correlação mais apropriada para as curvas de equilíbrio. A capacidade de adsorção desses equilíbrios pode ser obtida pela medida da isoterma de adsorção dos corantes reativos no adsorvente. ${ }^{32}$

A relação entre a quantidade de íons do corante adsorvida na superfície do adsorvente e a concentração na fase aquosa no equilíbrio foi investigada para soluções individuais dos corantes. Para interpretação dos dados experimentais foram empregados os modelos de isotermas de adsorção de Langmuir, Freundlich e Dubinin-Radushkevich. A isoterma de Langmuir assume que a superfície do adsorvente é uniforme, com sítios de adsorção energicamente idênticos..$^{33,34}$

$$
Q_{e}=\frac{Q_{m} \cdot K_{L} \cdot C_{e q u i l .}}{1+K_{L} \cdot C_{e q u i l .}}
$$

onde, $Q_{m}$ é a quantidade máxima de íons adsorvidos, $C_{\text {equil. }}$ é a concentração de íons em solução no equilíbrio e $K_{L}$ é constante de adsorção.

A concentração $C_{\text {equil. }} \rightarrow 0$, então $1+K_{L} C_{\text {equil. }} \rightarrow 1$, neste caso, a equação se torna uma isoterma linear $Q_{e}=K_{L} \cdot C_{e} \cdot Q_{m}$, obedecendo a Lei de Henry para soluções diluídas.

No modelo de Langmuir, os sítios de adsorção são todos de mesma energia, porém, em muitos casos, a adsorção pode não se ajustar a este modelo de isoterma. Em algumas situações, a isoterma de Freunclich proporciona melhores ajustes dos dados experimentais. ${ }^{33} \mathrm{~A}$ isoterma de Freundlich descreve o equilíbrio em superfícies heterogêneas e, por esta razão, não assume uma capacidade de adsorção em monocamada.

$$
Q_{e}=K_{F} \cdot C_{\text {equil }}^{b F}
$$

Esta equação sugere que a concentração do adsorvato na superfície do adsorvente aumenta à medida que também aumenta a concentração do adsorbato na solução. $K_{F}$ representa a capacidade do adsorvente $\left(\mathrm{mg} \mathrm{g}^{-1}\right)$ e $b_{F}$ (adimensional) é o fator que indica a heterogeneidade da superfície do adsorvente. Os valores de $b_{F}$ variam entre 0 e 1 , sendo que quanto mais heterogênea a superfície mais o valor de $b_{\mathrm{F}}$ se aproximará de zero. ${ }^{33}$

Esta isoterma é largamente recomendada para estudos em superfície heterogênea, entretanto este modelo não converge com a lei de Henry em baixas concentrações do adsorbato, ou seja, em baixa cobertura da superfície do adsorvente.

A isoterma de Dubinin-Radushkevich é aplicada para distinguir se o processo de adsorção é de natureza física ou química. Baseando-se no modelo de Dubinin-Radushkevich, a vizinhança da superfície do sólido é caracterizada por uma série de equipotenciais superficiais tendo o mesmo potencial de sorção. ${ }^{34-37}$

A isoterma é similar ao modelo de Langmuir, mas não assume superfície homogênea ou energia potencial constante. A isoterma de Dubinin-Radushkevich pode ser representada pela equação

$$
q_{e}=q_{m} \exp \left(-K \varepsilon^{2}\right)
$$

onde $q_{e}$ é a quantidade de soluto adsorvido em $\left(\mathrm{mol} \mathrm{g}^{-1}\right), q_{m}$ é a capacidade máxima de adsorção $\left(\mathrm{mol} \mathrm{g}^{-1}\right), K$ é a constante de energia de adsorção em $\mathrm{mol}^{2} \mathrm{kj}^{-2}$ e $\varepsilon$ é o potencial polanyi. O potencial polanyi (ع) pode ser obtido pela Equação 5:

$$
\varepsilon=R T \ln \left(1+\frac{1}{C_{\text {equil. }}}\right)
$$

onde $R$ é a constante universal dos gases $\left(\mathrm{kJ} \mathrm{mol}^{-1} \mathrm{~K}^{-1}\right), T$ a temperatura (K) e $\mathrm{C}_{\text {equil. }}$ é a concentração de equilíbrio na fase líquida ( $\left.\mathrm{mol} \mathrm{L}^{-1}\right)$.

A constante de Dubinin-Radushkevich, $K$, está relacionada à energia média de sorção $(E)$ através da Equação 6

$$
E=\frac{1}{\sqrt{-2 K}}
$$

A energia média de sorção, $\mathrm{kj} \mathrm{mol}^{-1}$, é a energia livre envolvida na transferência de $1 \mathrm{~mol}$ de soluto da solução para a superfície do adsorvente. Se o processo de adsorção é de natureza física, a média da energia de adsorção é de $1-8 \mathrm{~kJ} \mathrm{~mol}^{-1}$, enquanto que, no caso de adsorção química é maior do que $8 \mathrm{~kJ} \mathrm{~mol}^{-1}$

A equação de Dubinin-Radushkevich, na sua forma linear, é dada pela equação 


$$
\ln q_{e}=\ln q_{m}-K \varepsilon^{2}
$$

O gráfico de $\ln q_{e}$ vs $\left[R T \ln \left(1+1 / C_{e}\right)\right]^{2}$ fornece os valores de $q_{m} \mathrm{e}$ $K$ através dos coeficientes linear e angular das retas obtidas.

As isotermas de adsorção dos corantes reativos adsorvidos pelo sal de quitosana quaternário a $25^{\circ} \mathrm{C}$ são ilustradas na Figura 7.

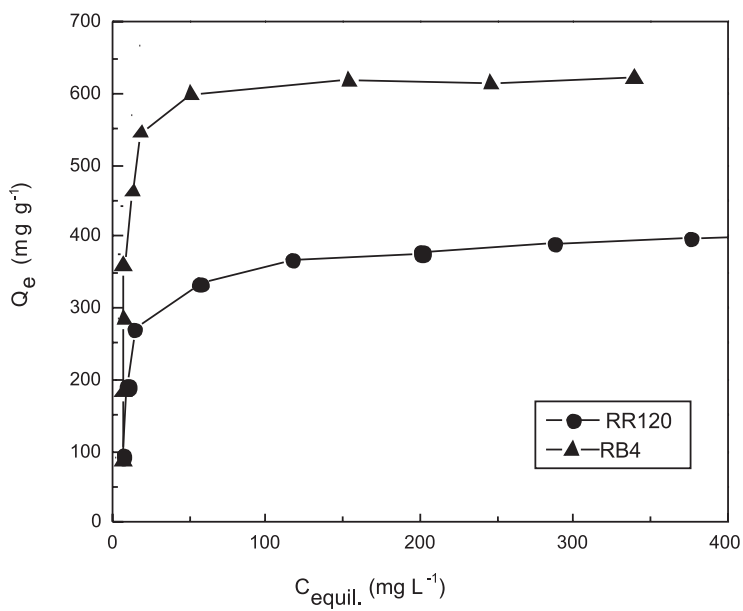

Figura 7. Isotermas de adsorção dos corantes $(\mathbf{\Delta})=R B 4,(\mathbf{O})=R R 120, p H$ $4 \mu=0,1 \mathrm{~mol} \mathrm{~L}^{-1}$, velocidade de agitação $250 \mathrm{rpm}$, tempo de contato $=19 \mathrm{~h}$ (RB4) e $56 h$ (RR120) e temperatura $25^{\circ} \mathrm{C}$

A isoterma indica que a quantidade adsorvida aumenta com a concentração de equilíbrio do corante na solução, devido à saturação progressiva da monocamada para os dois sistemas estudados. A partir da saturação da monocamada, a capacidade de adsorção não dependeu da concentração inicial do corante na solução, indicando que ocorreu uma forte afinidade entre as moléculas do corante e os sítios na superfície do adsorvente.

A isoterma de adsorção foi analisada colocando-se as Equações de Langmuir, Freundlich e Dubinin-Radushkevich em suas formas lineares, sendo que a equação que melhor ajustou os dados de adsorção foi selecionada para determinação dos parâmetros de adsorção. As equações e os coeficientes de correlação dos modelos de isotermas são apresentados na Tabela 1.

Tabela 1. Equação linear das isotermas de Langmuir, Freundilich e DubininRadushkevich

\begin{tabular}{lcccr}
\hline Equação & RR120 & $\mathrm{R}^{2}$ & $\mathrm{RB} 4$ & $\mathrm{R}^{2}$ \\
\hline Langmuir & $\mathrm{Y}=3,72 \cdot 10^{-2}+2,41 \cdot 10^{-3} \mathrm{X}$ & $1,000 \mathrm{Y}=1,14 \cdot 10^{-2}+1,57 \cdot 10^{-3} \mathrm{X}$ & 0,999 \\
Freundlich & $\mathrm{Y}=2,00+0,245 \mathrm{X}$ & 0,742 & $\mathrm{Y}=2,20+0,157 \mathrm{X}$ & 0,864 \\
D-R & $\mathrm{Y}=-7,32-2,0.10^{-3} \mathrm{X}$ & 0,774 & $\mathrm{Y}=-5,81-2,59 \cdot 10^{-3} \mathrm{X}$ & 0,532 \\
\hline
\end{tabular}

A partir do coeficiente de correlação linear $\left(\mathrm{R}^{2}\right)$, o melhor ajuste dos dados experimentais foi obtido empregando-se a isoterma de Langmuir, e esta foi escolhida para determinação dos parâmetros de adsorção dos corantes reativos RR120 e RB4 pelo adsorvente quitosana.

A capacidade máxima de saturação da monocamada do adsorvente foi de 415 e $637 \mathrm{~g}$ de corante por grama de adsorvente e a constante de Langmuir foi 0,065 e $0,138 \mathrm{~L} \mathrm{mg}^{-1}$, respectivamente.

A menor afinidade de adsorção do RR120 pode ser atribuída ao tamanho e à geometria molecular do corante, que produz um impedimento estérico maior, dificultando a interação com o adsorvente.

\section{CONCLUSÕES}

O espectro no infravermelho do sal quaternário de quitosana mostrou um pico em $1482 \mathrm{~cm}^{-1}$, o qual comprovou a introdução dos grupos quaternários na superfície da quitosana, e a análise condutimétrica forneceu um grau de substituição de 0,46.

Dois modelos de cinética de adsorção foram testados: pseudoprimeira ordem e pseudossegunda ordem. Os dados experimentais ajustaram-se melhor ao modelo de pseudossegunda ordem, o qual forneceu uma constante de velocidade, $\mathrm{k}_{2}$, de $2,82 \times 10^{-5}$ e $1,04 \mathrm{x}$ $10^{-4} \mathrm{~g} \mathrm{mg}^{-1} \mathrm{~min}^{-1}$ para os corantes RR120 e RB4, respectivamente.

O mecanismo de adsorção entre o SQQ e os corantes reativos RR120 e RB4 ocorreu por via interação iônica, entre os sítios do adsorvente e os grupos aniônicos dos corantes.

Os valores da capacidade de adsorção mais baixos para corante RR120 podem ser atribuídos ao efeito estérico em função do tamanho e disposição planar da molécula deste corante, que teve maior dificuldade de interagir com os sítios de adsorção do adsorvente.

\section{MATERIAL SUPLEMENTAR}

A Figura 1S mostra o espectro no infravermelho da quitosana. A Figura $2 \mathrm{~S}$ representa o modelo cinético de pseudoprimeira ordem. A Figura 3S representa o modelo cinético de pseudossegunda ordem. Este material está disponível em http://quimicanova.sbq.org.br, na forma de arquivo .PDF, com acesso livre.

\section{REFERÊNCIAS}

1. http://www.brasildasaguas.com.br/brasil_das_aguas/importancia_agua, acessada em Julho 2010.

2. Kao, C. M.; Chou, M. S.; Fang, W. L.; Liu, B. W.; Huang, B. R.; Chemosphere 2001, 44, 1055.

3. Kunz, A.; Peralta-Zamora, P.; de Moraes, S. G.; Duran, N.; Quim. Nova 2002, 25, 78 .

4. Crini, G.; Bioresour. Technol. 2006, 97, 1061.

5. Guaratini, C. C. I.; Zanoni, M. V. B.; Quim. Nova 2000, 23, 71.

6. Santos, A. B.; Eng. San. Ambient. 2005, 10, 253.

7. Kumar, K. V.; Ramamurthi, V.; Sivanesan, S.; Dyes Pigm. 2006, 69, 102.

8. Tünay, O.; Water Sci. Technol. 1996, 34, 9

9. Meriç, S.; Selçuk, H.; Belgiorno, V.; Water Resour. 2005, 39, 1147.

10. Anjaneyulu, Y.; Chary, N. S.; Raj, D. S. S.; Rev. Environ. Sci. Bio/ Technol. 2005, 4, 245.

11. Robinson, T.; Chandran, B. ; Naidu, G. S.; Nigam, P.; Bioresour. Technol. 2001, 77, 247.

12. Baley, S.E; Olin, T. J.; Bricka, R. M.; Adrian, D. D.; Water Res. 1999, 33, 2469.

13. Reddad, Z.; Gerente C.; Andrés Y; Cloirec, P.; Environ. Sci. Technol. 2002, 36, 2067.

14. Evans, J. R.; Davids, W. G.; MacRae, J. D.; Amirbahman, A.; Water Res. 2002, 36, 3219.

15. Prasad, M.; Saxena, S.; Ind. Eng. Chem. Res. 2004, 43, 1512.

16. Nigam, P.; Banat, L. M.; Singh, D.; Merchant, R.; Process Biochem. 1999, 31, 435.

17. Ngah, W. S. W.; Endud, C. S.; Mayanar, R.; React. Funct. Polym. 2002, $50,181$.

18. Crini, G.; Badot, P. M.; Prog. Polym. Sci. 2008, 33, 399.

19. Qin, Q.; Ma, J.; Liu, K.; J. Hazard. Mater. 2009, 162, 133

20. Varma, A. J.; Deshpande, S. V.; Kennedy, J. F.; Carbohydr Polym. 2004, 55,3219 .

21. Juang, R.; Tseng, R. K. L.; Wu, F. C.; Lee, S.H.; J. Chem. Tech. Biotechnol. 1997, 70, 391.

22. Kimura, I. Y.; Laranjeira, M. C. M.; Fávere, V. T.; Int. J. Polym. Mater. 2002, 51, 284.

23. Chiou, M.; Ho, P.; Li, H.; Chemosphere 2003, 50, 1095. 
24. Cestari, A. R.; Vieira, A. F. S.; Santos, A. G. P.; Mota, J. A.; Almeida, V. P.; J. Colloid Interface Sci. 2004, 280, 380.

25. Sakkayawong, N.; Thiravetyan, P.; Nakbapote, W.; J. Colloid Interface Sci. 2005, 286, 36

26. Uzun, I.; Dyes Pigm. 2006, 70, 76.

27. Inoue, K.; Yoshizuka, K. O. K.; Anal. Chim. Acta 1999, 388, 209.

28. Chassary, P.; Vincent, T.; Guibal, E.; React. Funct. Polim. 2004, 60, 137.

29. Rosa, S.; Laranjeira, M. C. M.; Riela, H. G.; Fávere, V. T.; J. Hazard. Mater. 2008, 155, 253.

30. Brugnerotto, J.; Lizardi, J.; Goycoole, F. M.; Argüelles-Monal, W.; Desbrières, J.; Rinaudo, M.; Polymer 2001, 42 , 3569.
31. Ho, Y. S.; Mckay, G.; Process Biochem. 1999, 34, 451.

32. Cheung, W. H.; Szeto, Y. S.; Mckay, G.; Bioresour. Technol. 2009, 100, 1143.

-33. Mckay, G.; Use of adsorbents for the removal of pollutants from wastewater, CRC Press: Florida, 1996.

34. Özcan, A.; Özcan, A. S.; Tunali, S.; Akar, T.; Kiran, I.; J. Hazard. Mater. 2005, 124, 200

35. Ünlü, N.; Ersoz, M.; J. Hazard. Mater. 2006,136, 272.

36. Tripathy, S. S.; Raichur, A. M.; J. Hazard. Mater. 2008, 153, 1043.

37. Chen, A. H.; Yang, C. Y.; Chen, C. Y.; Chen, C. W.; J Hazard. Mater. 2009, 163, 1068. 


\section{CLORETO DE N-(2-HIDROXIL) PROPIL-3-TRIMETIL AMÔNIO QUITOSANA COMO ADSORVENTE DE} CORANTES REATIVOS EM SOLUÇÃO AQUOSA

Valfredo T. Fávere*

Departamento de Química, Universidade Federal de Santa Catarina, CP 476, 88040-900 Florianópolis - SC, Brasil

Humberto G. Riella

Departamento de Engenharia Química, Universidade Federal de Santa Catarina, 88040-900 Florianópolis - SC, Brasil

\section{Sirlei da Rosa}

Universidade Tecnológica Federal do Paraná, Curitiba - PR, Brasil



Figura 1S. Espectro no infravermelho da quitosana

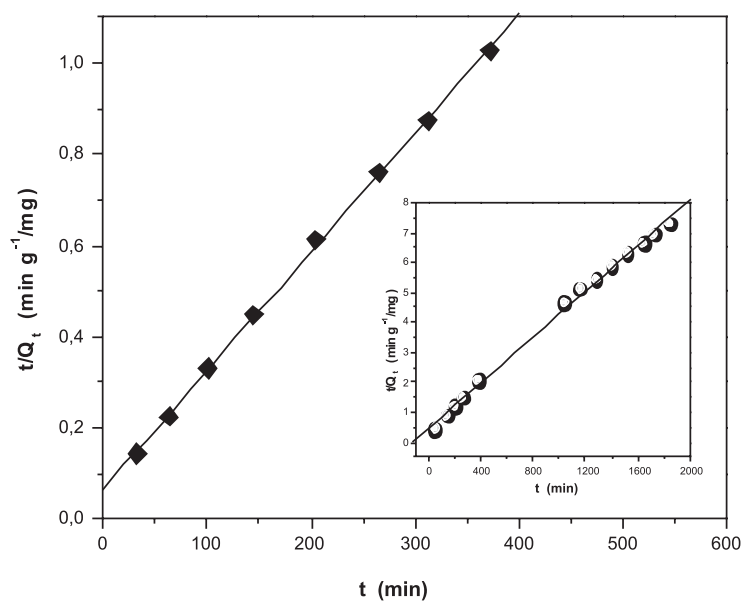

Figura 3S. Modelo cinético de pseudossegunda ordem ( ) corante RB4, (·) corante RR120

*e-mail: favere@qmc.ufsc.br



Figura 2S. Modelo cinético de pseudoprimeira ordem (•) corante RB4, (·) corante RR120 